\title{
Kinetics and Mechanical Studies of Melaminium bis(trichloroacetate) dihydrate
}

\author{
N. Kanagathara ${ }^{a}$, M.K. MarchewKa ${ }^{b}$, S. GUnASEKARAN $^{c}$ And G. Anbalagan ${ }^{d, *}$ \\ ${ }^{a}$ Department of Physics, Vel Tech Dr. RR \&Dr. SR Technical University, Avadi, Chennai-62, India \\ ${ }^{b}$ Institute of Low Temperature and Structure Research, Polish Academy of Sciences \\ P.O. Box 937, 50-950 Wrocław 2, Poland \\ ${ }^{c}$ St. Peter's University, Avadi, Chennai-54, India \\ ${ }^{d}$ Department of Physics, Presidency College, Chennai-5, India
}

(Received October 28, 2013)

The thermal decomposition kinetics of melaminium bis(trichloroacetate) dihydrate (MTCA) has been studied by thermogravimetry and derivative thermogravimetry techniques using non-isothermal experiments at three different heating rates 10,15 , and $20^{\circ} \mathrm{C} \mathrm{min}{ }^{-1}$. Non-isothermal studies of MTCA revealed that the decomposition occurs in three stages involving dehydration and decomposition. The apparent activation energy $\left(E_{\mathrm{a}}\right)$ and the pre-exponential factor $(\ln A)$ of each stage of thermal decomposition at various linear heating rates are calculated using Flynn-Wall, Friedman, Kissinger, and Kim-Park method. A significant variation of effective activation energy $\left(E_{\mathrm{a}}\right)$ with conversion $(\alpha)$ indicates that the process is kinetically complex. The linear relationship between the $A$ and $E_{\text {a }}$ values is well established (compensation effect). Isothermal kinetics of thermal decomposition of MTCA was found to obey Avrami-Erofeev's (A4) and power law (P3) equations. In addition to the above, mechanical properties have been estimated by Vicker's microhardness test for the grown crystal.

DOI: 10.12693 /APhysPolA.126.827

PACS: 82.20.Pm; 65.40.-b; 82.20.-w; 62.20.Qp; 83.50.-v

\section{Introduction}

Since organic crystals do fall short of vital technological properties such as enhanced stability, mechanical strength, and performance at low and high temperature, to retain the merits and to overcome the shortcomings of the organic materials, some new classes of semi-organic nonlinear optical (NLO) crystals have been developed. Semi organic nonlinear optical materials are reputed candidates for device fabrication technology, owing to their large nonlinear coefficient, high laser damage threshold, good mechanical and thermal stability $[1,2]$.

MTCA is one such semi organic NLO crystal characterized for its NLO property. The lifetime of crystal can be explored with the knowledge of mechanical and thermal stability of the crystal. Moreover, improvements of crystal quality also depend on knowing the thermodynamical properties and thermal stabilities of the crystals and the information are needed to avoid unwanted structural changes during storage and formulation.

Melamine is an important industrial chemical which has uses in resins and plastics. The reaction of melamine with formaldehyde gives thermosetting resins of industrial importance. Melamine family crystals have over the years been subjected to extensive investigation by several researchers for their nonlinear optical properties. Marchewka et al. [3-5] revealed the suitability of melamine family of crystals for their nonlinear optical properties and future applications.

* corresponding author
In recent years, the application of thermogravimetric (TG) and derivative thermogravimetric (DTG) to study the thermal decomposition behavior has gained a wide acceptance among researchers. TG is used to determine the thermal decomposition kinetics and thermal stability of polymers. Attempts have been made to calculate influencing kinetic data during thermal degradation. Several researchers have already studied the thermal behavior of melamine [6, 7]. Recently, Kanagathara et al. reported the thermal decomposition behavior of some melaminium salts $[8,9]$.

According to ICTAC kinetics committee, multiple heating rate programs are recommended. Since this method results only in fewer errors than single heating rate method, to estimate kinetic parameters for the thermal decomposition of polymer composites, multiple heating rate method is applied. The crystal structure of MTCA was reported by Perpetuo and Janczak [10]. Vibrational and other properties of MTCA were recently reported by Debrus et al. [5] and Kanagathara et al. [11] Although many reports available for the thermal behavior of melamine and its salts, not much research has been carried out on the kinetic analysis of the thermal decomposition of MTCA. Single crystal X-ray diffraction analysis confirms that MTCA crystallizes in monoclinic $(C 2)$ structure and the calculated lattice parameters are $a=17.70 \AA, b=8.44 \AA, c=6.09 \AA, \alpha=90^{\circ}$, $\beta=100.24^{\circ}, \gamma=90^{\circ}$ and $V=900 \AA^{3}$ [9].

Hence, in continuation of our work on melamine based compounds, in the present study an attempt is made to study the thermal stability of MTCA. Dissociation mechanism and kinetic parameters have been done by em- 
ploying physical model-dependent methods and model-free methods. Since microhardness has direct correlation with the crystal structure and is sensitive to lattice perfection, interatomic spacing [12], mechanical properties have been studied by employing Vicker's microhardness tester for the first time.

\section{Experimental procedure}

Single crystals of MTCA $\left[\mathrm{C}_{3} \mathrm{H}_{8} \mathrm{~N}_{6}^{2+} \cdot 2 \mathrm{C}_{2} \mathrm{Cl}_{3} \mathrm{O}_{2}^{-} \cdot 2 \mathrm{H}_{2} \mathrm{O}\right]$ have been grown from aqueous solution by slow solvent evaporation method at room temperature. The double distilled water was used as a solvent. AR grade samples of melamine and trichloroacetic acid were taken in 1:3 ratio. The dissolved acid was added dropwise to the hot solution of melamine. The solution was stirred well using magnetic stirrer, filtered and then allowed to cool at room temperature. The purity of the synthesized salt was further improved by re-crystallization process. Tiny, transparent, colourless crystals were harvested in a growth period of 20-25 days by taking the following reaction

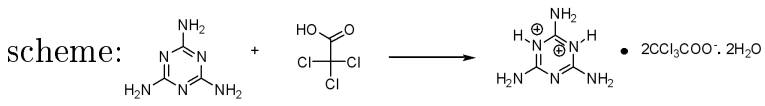

\section{Results and discussion}

\subsection{Thermal decomposition of $M T C A$}

The thermal behavior of MTCA has been studied at 10,15 and $20^{\circ} \mathrm{C} \mathrm{min}^{-1}$ by using a SDT Q $6000 \mathrm{~V} 8.2$ Built 100 thermal analyzer. All the experiments are non-isothermal and carried out under nitrogen atmosphere in the temperature range of $30-400{ }^{\circ} \mathrm{C}$. The $\mathrm{TG}$ and DTG curves of MTCA at various heating rates in nitrogen are shown in Fig. 1. In the presence of nitrogen, the DTG curves showed a single peak, implying that the thermal decomposition process occurred in a single step. As the heating rate was increased, the temperature at initial thermal decomposition and the maximum decomposition rate shifted toward a higher temperature. Thus heating rate and the atmosphere significantly influence the thermal decomposition [13].

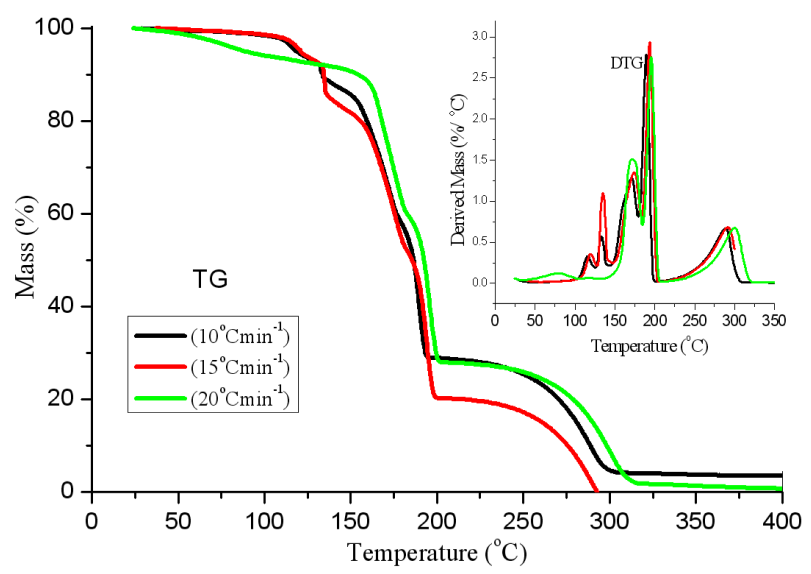

Fig. 1. TG-DTG curves of MTCA at a heating rate of 10,15 , and $20{ }^{\circ} \mathrm{C} \min ^{-1}$.
It is seen from Fig. 1 that the decomposition of MTCA occurs in three stages involving dehydration and decomposition. In the first stage, that takes place below $\pm 135^{\circ} \mathrm{C}$, it suggests that hydrated water (I stage) of MTCA is eliminated from the structure of MTCA and the corresponding exothermic DTG peak is obtained at $\pm 130{ }^{\circ} \mathrm{C}$. A rapid mass loss of nearly $\pm 60 \%$ occurs during the second stage which is due to the elimination of trichloroacetate anions (II stage) attributed by two exothermic peaks in DTG. The remaining weight loss is due to elimination of melaminium cation (III stage). The DTG curve shows an exothermic peak at about $\pm 170{ }^{\circ} \mathrm{C}$ immediately followed by sharp exothermic peak at $\pm 195{ }^{\circ} \mathrm{C}$ which is the melting point of the material coinciding with a major weight loss due to decomposition as shown in TGA. A small hump before $170^{\circ} \mathrm{C}$ of MTCA is seen in DTG curve which is the phase transition where the two water molecules are eliminated in this stage. From this it is identified that MTCA has more thermal stability and this enables the suitability of the crystal for thermal applications.

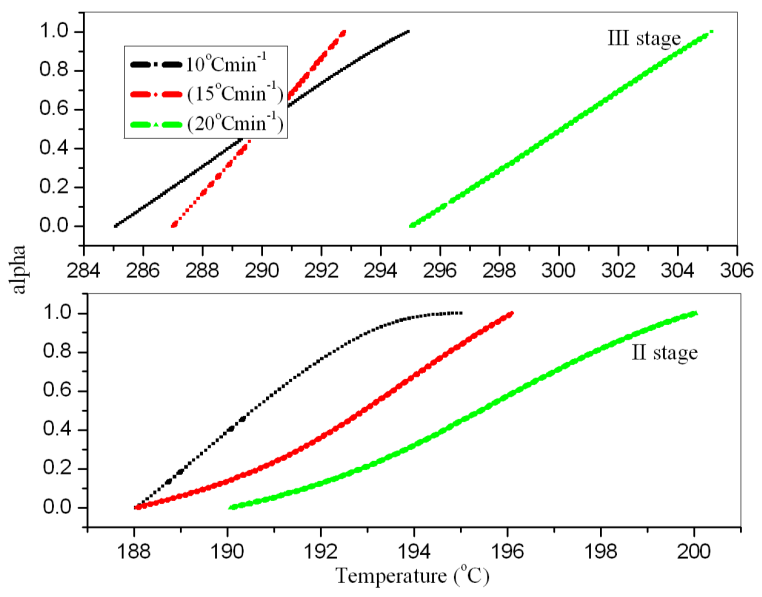

Fig. 2. Fraction reacted, $\alpha$ versus temperature for stages II and III at three different heating rates 10, 15, and $20{ }^{\circ} \mathrm{C} \mathrm{min}{ }^{-1}$.

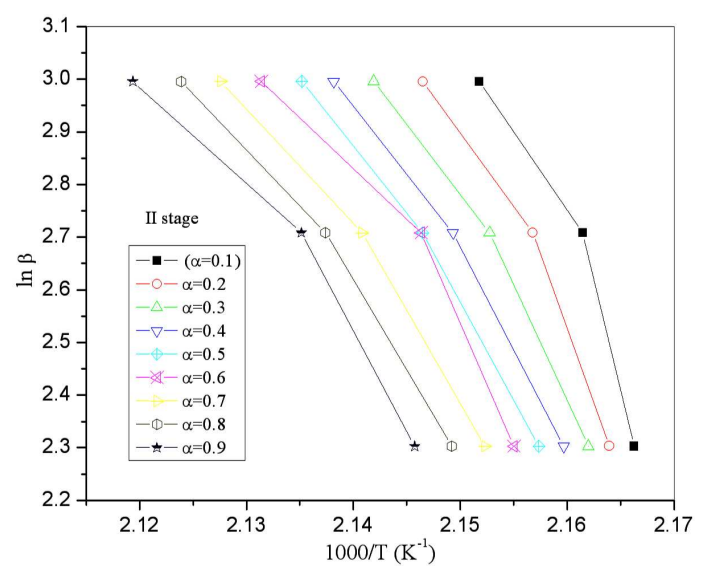

Fig. 3. Flynn-Wall plot for stage II in nitrogen atmosphere for the non-isothermal decomposition of MTCA. 


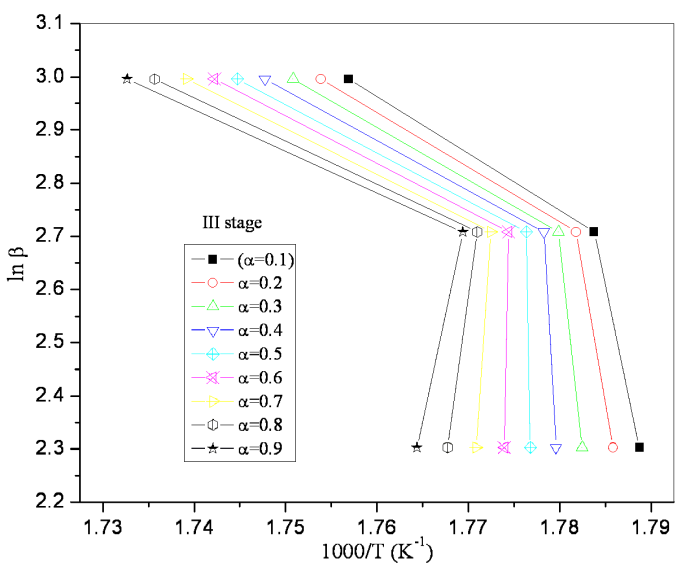

Fig. 4. Flynn-Wall plot for stage III in nitrogen atmosphere for the non-isothermal decomposition of MTCA.
Figure 2 shows the alpha-temperature curves for the decomposition of MTCA in nitrogen atmosphere at three different heating rates 10,15 , and $20^{\circ} \mathrm{C}$ min $^{-1}$. It can be observed that $\alpha-T$ curves at all considered heating rates has the same shapes. Increasing of heating rate leads to increase of the peak temperature value from $192.22^{\circ} \mathrm{C}$ to $195.11^{\circ} \mathrm{C}$ during the II stage and $290.99^{\circ} \mathrm{C}$ to $300.50{ }^{\circ} \mathrm{C}$ during the III stage. The kinetics of thermal decomposition of MTCA at three different heating rates is studied by three different multiple heating methods: Flynn-Wall, Kissinger, and Kim-Park [14-16]. Typical Flynn-Wall plots constructed to evaluate the steps are presented in Figs. 3 and 4 for the II stage and III stage, respectively, and the straight lines obtained are nearly parallel to each other. At each heating rate, the temperatures were determined corresponding to degree of conversion $\alpha$ within the range 0.1 to 0.9 in intervals of 0.1 .

TABLE I

Kinetic parameters of non-isothermal decomposition of MTCA by Flynn-Wall and Friedman methods.

\begin{tabular}{c|c|c|c|c|c|c|c|c}
\hline \hline \multirow{2}{*}{$\alpha$} & \multicolumn{3}{|c|}{ Flynn-Wall method } & \multicolumn{4}{c}{ Friedman method } \\
\cline { 2 - 8 } & \multicolumn{2}{|c|}{ Stage II } & \multicolumn{2}{c|}{ Stage III } & \multicolumn{2}{c}{ Stage II } & \multicolumn{2}{c}{ Stage III } \\
\cline { 2 - 8 } & $\begin{array}{c}E_{\mathrm{a}} \\
{\left[\mathrm{kJ} \mathrm{mol}^{-1}\right]}\end{array}$ & $\ln A$ & $\begin{array}{c}E_{\mathrm{a}} \\
{\left[\mathrm{kJ} \mathrm{mol}^{-1}\right]}\end{array}$ & $\begin{array}{c}\ln A \\
{\left[\mathrm{~s}^{-1}\right]}\end{array}$ & $\begin{array}{c}E_{\mathrm{a}} \\
{\left[\mathrm{kJ} \mathrm{mol}^{-1}\right]}\end{array}$ & $\ln A$ & $\begin{array}{c}E_{\mathrm{a}} \\
{\left[\mathrm{kJ} \mathrm{mol}^{-1}\right]}\end{array}$ & $\ln A$ \\
\hline 0.1 & 375.97 & 41.41 & 150.31 & 22.09 & 226.87 & 62.39 & 147.35 & 33.72 \\
0.2 & 323 & 35.19 & 145.48 & 16.94 & 243.39 & 66.67 & 144.17 & 33.01 \\
0.3 & 285.49 & 30.79 & 140.75 & 14.09 & 250.86 & 68.57 & 140.99 & 32.29 \\
0.4 & 267.11 & 28.66 & 134.02 & 13.34 & 259.58 & 70.76 & 59.31 & 14.78 \\
0.5 & 259.24 & 27.74 & 129.17 & 12.79 & 272.1 & 73.93 & 131.89 & 30.28 \\
0.6 & 234.57 & 24.87 & 126.31 & 12.47 & 257.16 & 69.98 & 55.55 & 13.95 \\
0.7 & 232.18 & 24.59 & 121.41 & 11.92 & 262.99 & 71.33 & 126.46 & 29.03 \\
0.8 & 226.27 & 23.91 & 113.15 & 10.99 & 264.73 & 71.58 & 119.59 & 27.51 \\
0.9 & 213.28 & 22.41 & 106.51 & 10.26 & 240.84 & 65.21 & 107.61 & 24.88 \\
& \multicolumn{7}{r}{}
\end{tabular}

Activation energy $\left(E_{\mathrm{a}}\right)$ is calculated from the slope of $\ln \beta$ versus $1 / T$ for a fixed mass loss and it is given in Table I. We have also calculated activation energies by the Friedman method for all the three stages and it is given in Table I. The calculated values of the activation energy in the Flynn-Wall method very well agree with the Friedman. Activation energies of the decomposition complex were also calculated by Kissinger and Kim-Park. Both methods yield similar calculation results, which are therefore reasonable (Table II). The real activation energy for each decomposition step would be the one obtained under lowest heating rate.

Dependence of effective activation energy $\left(E_{\mathrm{a}}\right)$ with extent of conversion $(\alpha)$ is used to identify its kinetic scheme i.e. these values are used for input to multi-step for model fitting purposes [17]. It is seen from Fig. 5A that during II as well as III stage of decomposition, $E_{\mathrm{a}}$ decreases with alpha during the entire conversion range $(0.1-0.9) . E_{\mathrm{a}}$ is high at the initial fraction reacted $(\alpha)$ which indicates that the decomposed products
TABLE II

Activation energies of thermal degradation of MTCA by Kissinger and Kim-Park methods.

\begin{tabular}{c|c|c|c|c}
\hline \hline \multirow{2}{*}{ Method } & \multicolumn{2}{|c|}{ Stage II } & \multicolumn{2}{c}{ Stage III } \\
\cline { 2 - 5 } & $E_{\mathrm{a}} /\left[\mathrm{kJ} \mathrm{mol}^{-1}\right]$ & $\ln A$ & $E_{\mathrm{a}}\left[\mathrm{kJ} \mathrm{mol}^{-1}\right]$ & $\ln A$ \\
\hline Kissinger & 217.45 & 46.58 & 148.73 & 21.55 \\
Kim-Park & 225.18 & 60.86 & 158.16 & 36.24
\end{tabular}

are in equilibrium with the gaseous reactants. Since $E_{\text {a }}$ varies strongly with extent of conversion indicates that the process is kinetically complex, i.e. multi-step mechanism [17, 18]. Effective activation energy is found to be higher for the II stage than the III stage. Kinetic compensation effect is observed in many isothermal processes. There is a linear relationship between $\ln A$ and $E_{\mathrm{a}}$ viz.

$$
\ln A=a E+b,
$$

where $a$ and $b$ are called compensation parameters. Figure $5 \mathrm{~B}$ shows the linear relationship between $\ln A$ and $E_{\mathrm{a}}$. It is seen from Fig. $5 \mathrm{~B}$ that the compensation effect is valid for the thermal decomposition of MTCA. 
TABLE III

Kinetic parameters and possible rate controlling processes of decomposition of MTCA.

\begin{tabular}{c|c|c|c|c|c}
\hline \hline $\begin{array}{c}\text { Kinetic } \\
\text { model }\end{array}$ & $\begin{array}{c}\text { Heating } \\
\text { rate } \\
{\left[{ }^{\circ} \mathrm{C} \mathrm{min}^{-1}\right]}\end{array}$ & $\begin{array}{c}E_{\mathrm{a}} \\
{\left[\mathrm{kJ} \mathrm{mol}^{-1}\right]}\end{array}$ & $\ln A$ & $\begin{array}{c}\text { Correlation } \\
\text { coefficient } \\
R\end{array}$ & $\begin{array}{c}\text { Std. } \\
\text { deviation }\end{array}$ \\
\hline A4 & 10 & 233.29 & 48.13 & 0.99318 & 0.01877 \\
II stage & 15 & 225.26 & 45.76 & 0.99488 & 0.01795 \\
& 20 & 194.31 & 37.47 & 0.97659 & 0.4496 \\
\hline P3 & 10 & 138.46 & 16.68 & 0.96137 & 0.02191 \\
III stage & 15 & 146.65 & 17.19 & 0.98311 & 0.01253 \\
& 20 & 140.69 & 16.58 & 0.97089 & 0.01876
\end{tabular}

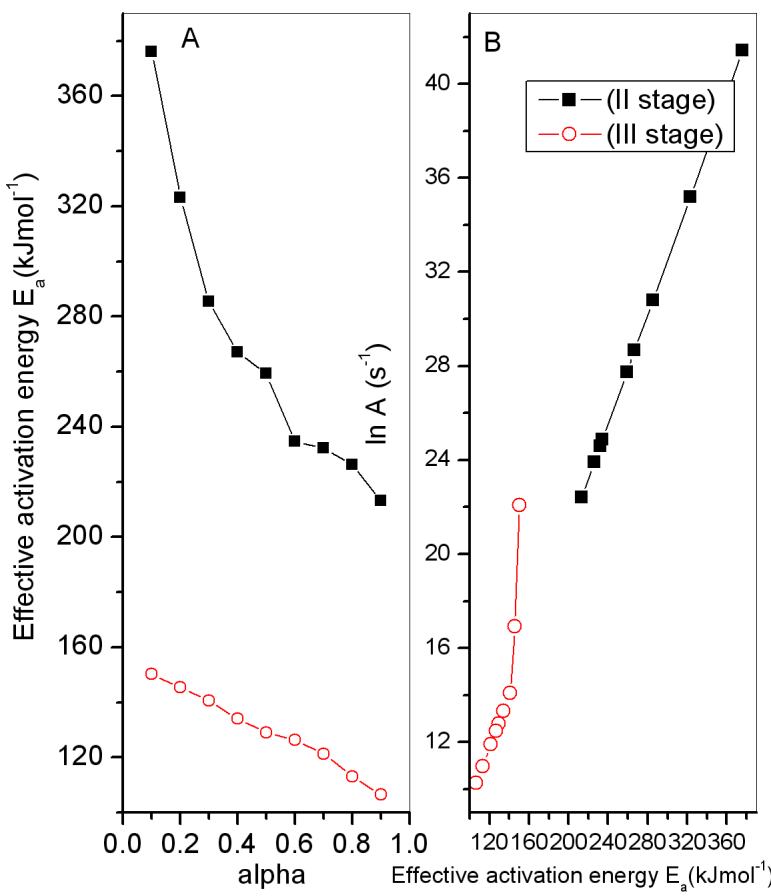

Fig. 5. (A) Variation of effective activation energy $\left(E_{\mathrm{a}}\right)$ versus fraction reacted $(\alpha)$ by Flynn-Wall method for three different stages II and III, (B) plot of pre-exponential factor $(\ln A)$ versus effective activation en$\operatorname{ergy}\left(E_{\mathrm{a}}\right)$.

\subsection{Dissociation mechanism/model fitting method}

Kinetic analysis by model fitting methods [19-21] was carried out to predict the mechanism of dissociation processes and to deduce the kinetic parameters. Kinetic analysis of TG data based on the rate equation

$$
\beta \mathrm{d} \alpha / \mathrm{d} t=A \exp (-E / R T) f(\alpha),
$$

states that the rate of the reaction is proportional to the rate coefficient with Arrhenius temperature dependence and a function of the degree of conversion. The integral form of Eq. (2) is given by the expression

$$
\ln \left(g(\alpha) / T^{2}\right)=\ln ((A R / \beta E)(1-2 R T / E))-E / R T,
$$

where $A$ is the pre-exponential factor, $E$ is the effective activation energy and $R$ is the gas constant. In the present study, all kinetic models (P4, P3, P2, P2/3, D1, $\mathrm{F} 1, \mathrm{~A} 4, \mathrm{~A} 3, \mathrm{~A} 2, \mathrm{D} 3, \mathrm{R} 3, \mathrm{R} 2$, and D2) are tested for all the three stages. A plot of $\ln \left(g(\alpha) / T^{2}\right)$ versus $1000 / T$ gives a straight line when the correct $g(\alpha)$ function is used in the equation is shown in Fig. 6. This $g(\alpha)$ function gives the mechanism of the reaction.

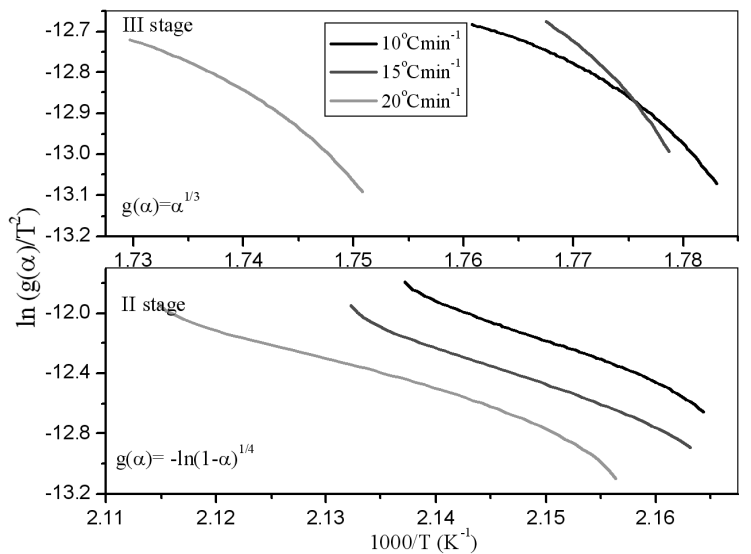

Fig. 6. Plot of $\ln \left(g(\alpha) / T^{2}\right)$ versus $1000 / T$ for stages II and III using TG data.

The kinetic parameters and possible rate controlling processes of decomposition of MTCA is given in Table III. Straight line with high correlation coefficient and low standard deviation values are selected to represent the possible controlling mechanism. The non-isothermal kinetic data of MTCA compound between the limit of $\alpha$ from 0 to 0.9 are fitted to all reaction models. By comparing the $E_{\mathrm{a}}$ values with the model-free method, it is found that II stage was accepted by Avrami-Erofeev's model (A4) and the III stage was accepted by power law (P3).

\subsection{Mechanical studies}

Microhardness study on the crystals brings out an understanding of the plasticity of the crystal. Hardness is a technique, in which a crystal is subjected to a relatively high pressure within a localized area. By suitable choice of indenter material and relatively simple equipment construction, hardness test can be easily carried out on all crystalline materials under various conditions of temperature and pressure. Deformation is local, so that a number of trials can be made on a single specimen of small dimensions and can be reproduced by maintaining the specimen indenter orientation relationship. Specimen of that relatively smooth surface is required. Hardness of a material is the resistance offered to indentation by a much harder body. It may be termed as a measure of the resistance against lattice destruction or the resistance offered to permanent deformation or damage. Hardness of the crystal carries information about the strength, molecular bindings, yield strength and elastic constants of the material. The good quality single crystals are very much needed for device fabrication with good mechanical strength [22-24]. In order to study the mechanical property, the Vickers microhardness measurement was carried out on the grown crystals. The microhardness studies were carried out on the grown 
crystal at room temperature on (110) plane for various loads ranging from $25 \mathrm{~g}$ to $100 \mathrm{~g}$. The diagonal lengths $(d)$ of the indented impressions obtained for various loads were measured using a micrometer eyepiece. For a particular load, at least three well-defined impressions were considered and the average of the all the diagonals $(d)$ was considered. The Vickers microhardness number $\mathrm{Hv}$ of the crystal was calculated using the relation,

$$
\mathrm{Hv}=1.8544\left(P / d^{2}\right) \text {, }
$$

where $\mathrm{Hv}$ is the Vickers hardness number in $\mathrm{kg} / \mathrm{mm}^{2}, P$ is the applied load in $\mathrm{kg}$, and $d$ is the average diagonal length of the indentation in $\mathrm{mm}$.

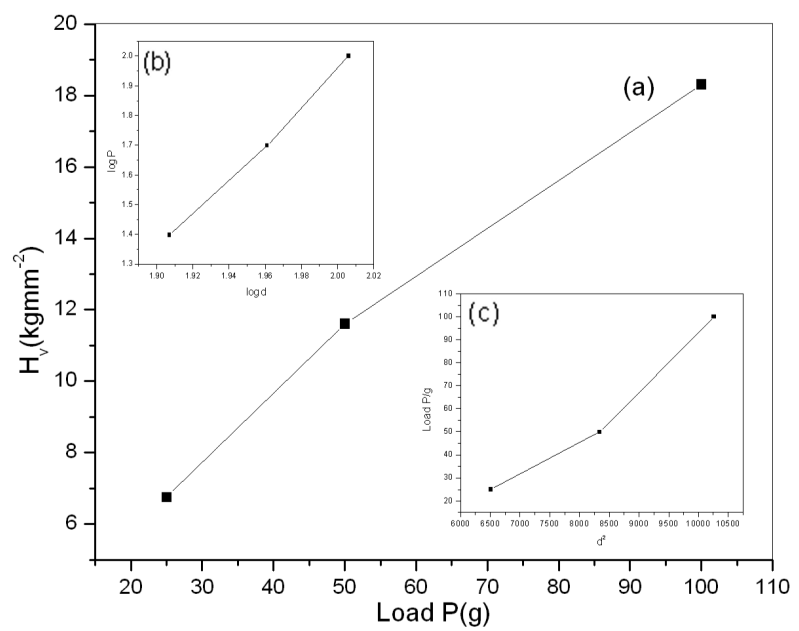

Fig. 7. (a) Variation of Vickers hardness $\mathrm{Hv}$ with load $P$, (b) plot of $\log P$ vs. $\log d$ and (c) plot of load $P$ vs. $d^{2}$.

Figure $7 \mathrm{a}$ shows the variation of hardness number (Hv) as a function of applied load ranging from 25 to $100 \mathrm{~g}$ for MTCA crystal. It is observed from the figure that the hardness number (Hv) increases with the increase of load which can be considered as the reverse indentation size effect (RISE) [24-26]. The cracks have been observed beyond $100 \mathrm{~g}$ for MTCA. It may be due to the internal stress released. In RISE, the material undergoes a relaxation, which involves a release of the indentation stress along the surface away from the indentation site, which may be because of the crack formation, dislocation activity, and/or elastic deformation of the tip of the indenter.

The Meyer work hardening coefficient is calculated from the Meyer law [27], which relates the load and indentation diagonal length as

$$
P=K_{1} d^{n}
$$

or

$$
\log P=\log K_{1}+n \log d,
$$

where $k$ is the material constant and $n$ is the Meyer index. The above Eq. (6) indicates that Hv should increase with $P$, if $n>2$ and decrease with $P$ when $n<2$. In order to calculate the value of the work hardening coefficient $n$, a graph is plotted between $\log P$ vs. $\log d$ and is shown in Fig. 7b. The slope of this line gives the value of $n$ and it is found to be 6.0641. According to Onistch [28], $n$ should lie between 1 and 1.6 for harder materials and above 1.6 for softer materials. The calculated $n$ value suggests that MTCA belongs to the soft material category.

The resistance pressure is defined as a minimum level of indentation load $(W)$ below which there is no plastic deformation [29]. Hayes and Kendall's theory [30] of resistance pressure explains a relationship between indentation test load $(P)$ and indentation size $(d)$ by assuming the following equation:

$$
P=W+K_{2} d^{2}
$$

where $W$ is the minimum load to initiate plastic deformation and $K_{2}$ is a load independent constant. These two values have been estimated from the plots drawn between $P$ versus $d^{2}$ shown in Fig. 7c, which is a straight line, where $W$ is the intercept along the load axis and $K_{2}$ is the slope. The corrected hardness $H_{0}$ for these crystals has been estimated using the relation

$$
H_{0}=1854 \times K_{2} \text {. }
$$

The minimum level of indentation load $(W)$ and corrected hardness value $\left(H_{0}\right)$ of the MTCA crystal are found to be $-109.0491 \mathrm{~g}$ and $37.08 \mathrm{~kg} / \mathrm{mm}^{2}$, respectively.

\section{Conclusion}

Single crystals of MTCA crystallize in the monoclinic system $(C 2)$. TG-DTG measurements were carried out at three different heating rates 10,15 , and $20^{\circ} \mathrm{C} \mathrm{min}^{-1}$. Model free methods: Flynn-Wall, Friedman, Kissinger and Kim-Park methods were employed. All methods yield almost similar results. It is found that Flynn-Wall and Kim-Park are the most suitable method to find effective activation energy. Effective activation energy $\left(E_{\mathrm{a}}\right)$ varies strongly with extent of conversion for the II and III stage which indicates the process is dominated by multi-step mechanism. The compensation effect is valid for the thermal decomposition of MTCA. From the results, it is concluded that Avrami-Erofeev's model (A4) and power law (P3) is the most probable kinetic model for the thermal decomposition of MTCA for the II stage and III stage, respectively. From microhardness test, it is observed that hardness number $\mathrm{Hv}$ increases with the increase in load and the work hardening coefficient $(n)$ is calculated to be 6.0641 which suggests that MTCA material belongs to soft material category.

\section{References}

[1] D. Sonal, S. Gupta Ranjith, A. Pardhan, O. Mareano, Noureddine Melikechi, C.F. Desai, J. Appl. Phys. 3.91, 3125 (2002).

[2] R. Ittyachan, P. Sagayaraj, J. Cryst. Growth. 243, 356 (2002).

[3] M.K. Marchewka, J. Baran, A. Pietraszko, A. Haznar, S. Debrus, H. Ratajczak, Solid State Sci. 5, 509 (2003).

[4] M.K. Marchewka, J. Janczak, S. Debrus, J. Baran, H. Ratajczak, Solid State Sci. 5, 643 (2003).

[5] S. Debrus, M.K. Marchewka, M. Drozd, H. Ratajczak, Opt. Mater. 29, 1058 (2007). 
[6] L. Costa, G. Camino, J. Therm. Anal. 34, 423 (1988).

[7] H. May, J. Appl. Chem. 9, 340 (1959).

[8] N. Kanagathara, M.K. Marchewka, N. Sivakumar, K. Gayathri, N.G. Renganathan, S. Gunasekaran, G. Anbalagan, J. Therm. Anal. Calorim. 112, 1317 (2013).

[9] N. Kanagathara, M.K. Marchewka, K. Pawlus, S. Gunasekaran, G. Anbalagan, J. Appl. Chem. 194576 1 (2013).

[10] G.J. Perpetuo, J. Janczak, Acta Crystallogr. C 62, o372 (2006)

[11] N. Kanagathara, N.G. Renganathan, M.K. Marchewka, N. Sivakumar, K. Gayathri, P. Krishnan, S. Gunasekaran, G. Anbalagan, Spectrochim. Acta A 101, 112 (2013).

[12] Jianghong Gong, J. Mater. Sci. Lett. 19, 515 (2000).

[13] Sang Mi Shin, Seong Hun Kim, Macromol. Res. 17, 149 (2009)

[14] H. Flynn, L.A. Wall, J. Polym. Sci. Part B, Polym. Lett. 4, 323 (1966).

[15] H.E. Kissinger, Anal. Chem. 29, 1702 (1957).

[16] S. Kim, J.K. Park, Thermochim. Acta 264, 137 (1995).

[17] M.E. Brown, M. Maciejewski, S. Vyazovkin, R. Nomen, J. Sempere, A. Burnham, J. Opfermann, R. Strey, H.L. Anderson, A. Kemmler, R. Keuleers, J. Janssens, H.O. Desseyn, Chao-Rui Li, T.B. Tang, B. Roduit, J. Malek, T. Mitsuhashi, Thermochim. Acta 355, 125 (2000).
[18] E.G. Prout, F.C. Tompkins, Trans. Faraday Soc. 40, 488 (1944).

[19] Jeya Rajendran, Lekshman Thanu Lingam, M. Jose, S. Jerome Das, J. Therm. Anal. Calorim. 103, 845 (2011).

[20] K. Joseph, R. Sridharan, T. Gnanasekaran, J. Nucl. Mater. 281, 129 (2000).

[21] J.J. Zhang, R.F. Wang, J.B. Li, H.M. Liu, J. Therm Anal. Calorim. 65, 241 (2001).

[22] B. Ducourant, R. Fourcade, G. Mascherpa, Rev. Chim. Miner. 20, 314 (1983)

[23] K. Li, X. Wang, D. Xue, Mater. Focus 1, 142 (2012).

[24] K. Sangwal, Mater. Chem. Phys. 63, 145 (2000).

[25] J. Gong, H. Miao, Z. Zhao, Z. Guan, Mater. Sci. Eng. A 303, 179 (2001).

[26] B. Basu, Mukhopadhyay, N.K. Manisha, J. Eur. Ceram. Soc. 29, 801 (2009).

[27] E. Meyer, Ph.D. thesis, Materials Testing Laboratory at the Imperial School of Technology, Charlottenburg, Germany, Draft, 1951.

[28] E.M. Onitsch, Microskopie 2, 131 (1947).

[29] V. Gupta, K. Bamzai, P.N. Kotru, B.M. Wanklyn, Mater. Chem. Phys. 89, 64 (2005).

[30] C. Hayes, E.G. Kendall, Metallography 6, 275 (1973). 